\title{
"How much money do you spend on gambling?" The comparative validity of question wordings used to assess gambling expenditure
}

\author{
Robert T. Wood and Robert J. Williams \\ University of Lethbridge \\ Lethbridge, Alberta, CANADA
}

Published in 2007 in: International Journal of Social Research Methodology: Theory \& Practice, Volume 10 (1), 63-77. 


\begin{abstract}
Gambling expenditure is a commonly asked question in jurisdiction-wide surveys of gambling behaviour and in surveys of household spending. However, the validity of self-reported gambling expenditure is questionable due to the fact that these expenditures usually do not match up with actual gambling revenue. The present study asked about past month gambling expenditure, in 12 different ways, to a random sample of 2424 Ontario adult gamblers. The relative validity of each question format was subsequently established by the correspondence of reported gambling expenditures with actual Ontario gambling revenue, as well as with amounts obtained by prospective diaries. Slight variations in question wording resulted in significant variation in reported expenditure amounts. However, certain question wordings elicited amounts closer to actual revenues and are therefore recommended for use in future surveys.
\end{abstract}




\section{Introduction}

Gambling expenditure is a commonly asked question in certain types of survey research. One type of survey where this is commonly asked are the jurisdiction-wide surveys of gambling behaviour, usually undertaken to ascertain the prevalence of problem gambling (e.g., Bondolfi, Osiek, Ferrero, 2000; Gerstein, et al., 1999; Götestam \& Johansson, 2003; Sproston, Erens, \& Orford, 2000). These expenditure figures are often then used to establish the average spending of social versus problem gamblers as well as what proportion of total gambling revenue comes from problem gamblers (e.g., Williams \& Wood, 2004a; 2004b). Another type of survey, which often asks about gambling expenditure, are the country-wide household expenditure surveys, usually undertaken to ascertain the relative allocation of disposable income (e.g., Australian Bureau of Statistics, 2005; Office for National Statistics, 2004; Statistics Canada, 2005; Statistics New Zealand, 2004). Outside of survey research, self-reported gambling expenditure is sometimes assessed in treatment outcome studies of problem gamblers (e.g., Hodgins \& Makarchuk, 2003).

Unfortunately, the validity of self-reported gambling expenditures is questionable as they rarely match up with actual gambling revenues. Household expenditure surveys have consistently obtained significant underestimates of actual gambling expenditure. For example, in Australia, gambling expenditure totals in the 1998-1999 Household Expenditure Survey were only $17.3 \%$ of actual gambling revenues (Access Economics, 2003). In New Zealand in 1998 people reported spending $\$ 103$ per person, compared to $\$ 280$ per person in actual revenue (Statistics New Zealand, 1999). In 2001, Canadians reported spending \$267 per household in the Survey of Household Spending, compared to an average of $\$ 447$ per person in actual revenue (Statistics Canada, 2003).

In gambling behaviour surveys, self-reported gambling expenditure has been both overreported and under-reported. In Washington State, Volberg et al. (1998) found that reported losses were 2 to 10 times higher than actual revenues, depending on the type of gambling. In a study of Canadian provinces by Williams \& Wood (2004a), self-reported expenditures were 2.1 times higher than actual provincial gaming revenues in that time period. In contrast, Australian and New Zealand studies have found self-reported expenditures to be between $1 / 2$ to $3 / 4$ of actual revenues (Abbott \& Volberg, 2000; Productivity Commission, 1999). In the national survey of U.S. citizens by the National Opinion Research Center, gamblers reported being ahead $\$ 3$ billion at the casinos in the past year instead of having left more than $\$ 20$ billion, which are the actual total revenues reported by the casino industry. Gamblers also reported being ahead $\$ 2$ billion at the racetrack and $\$ 4$ billion in private gaming. Only when it came to lotteries did they admit to a loss of $\$ 5$ billion (Gerstein et al., 1999).

There are several possible causes for these invalid self-reports. One concerns the ambiguity of the question being asked. Many of the gambling behaviour surveys have asked people "how much do you spend on gambling in a typical month". Using the term 'spend' may bias people toward reporting losses rather than wins. Although losses are much more common than wins, there are a few gamblers who do come out ahead (e.g., infrequent gamblers, lottery winners, professional sports handicappers, professional poker players). Moreover, if gambling activities also include the stock market, as they do in several of these surveys, then many more people are "winners". Another problem with the word 'spend" is that many people interpret it to mean how much total money they have wagered (outlay) rather than their net win/loss (Blaszcynski, Dumlao, \& Lange, 1997). Volberg et al. (1998) have speculated this was the 
interpretation in the Washington state study, where self-reported estimates were 2-10 times higher than revenues. Blaszcynski et al. (1997) also found that some people include travel and meal costs when reporting how much they 'spend' on gambling.

Paradoxically, studies using clearer nonbiased question wordings have obtained some of the most discrepant results. The National Opinion Research Center study (Gerstein, et al., 1999), asked U.S. citizens whether they had "come out ahead or behind on your gambling", with the choices being "ahead, behind, or broke even". With this wording, a majority of people actually reported winning rather than losing money in the past year. A similar type of wording has also been used in most of the Household Expenditure surveys, all of which have obtained significant underestimates of actual spending. For example, Statistics Canada asks people about their "expenses from [various types of gambling]" and then their "winnings from [various types of gambling]". It is a well established that the validity of reports concerning sensitive subject matter is strongly influenced by respondents' perceptions of the social desirability of their behavior (Fowler, 1993; Schaeffer, 2000; van der Heijden et al, 2000). When given the choice to represent themselves as either a 'winner' or 'loser' it would appear that many people choose to misrepresent themselves as winners or else minimize their actual losses.

Memory is another problem. Even if people correctly interpret the meaning of the question and attempt to answer honestly, their ability to accurately provide average net monthly gambling win/loss is doubtful. This is a difficult statistical calculation to make in the few seconds that most researcher-administered surveys provide. The fact is that these figures are usually not available and the person is just relying on their memory of these expenditures to make these calculations. Even if people are encoding their daily/weekly/monthly expenditures in terms of net win/loss, memories have differing valence, making them more or less available for retrieval (Tourangeau, 2000). Indeed, selective memory is a characteristic and well-documented feature of problem gambling (McCusker \& Gettings, 1997; National Research Council, 1999; Toneatto, 1999; Toneatto, et al., 1997).

There are superior ways of obtaining valid self-report, but, unfortunately, they are much more time consuming and/or costly. For example, prospective diaries consistently produce higher estimates of sensitive and socially undesirable behaviour, and these estimates come closest to matching objective measures of the behaviour when they have been available (e.g., per capita alcohol revenues) (Carney et al., 1998; Corti et al., 1990; Lemmens, Tan \& Knibbe, 1992). Similarly, the Time-Line Follow-Back (TLFB) is a retrospective procedure that guides the person through their past behaviour on a day by day basis using important dates or events as anchors (Sobell \& Sobell, 1996). This technique has been shown to produce more reliable (e.g., Hodgins \& Makarchuk, 2003) and more valid figures than questions that just ask for a global estimate of past month behaviour (e.g., O'Hare, 1991; Shakeshaft et al., 1999; Werch, 1990).

Obviously, techniques such as prospective diaries and the TLFB procedure should be used whenever feasible. Unfortunately, large scale population surveys of gambling behaviour or household spending are not one of these situations. In these contexts, gambling expenditure is typically one small item of interest among several hundred questions. What is needed here is research that sheds light on what retrospective gambling expenditure question wording is able to elicit the most valid estimates. This is the purpose of the present study. 


\section{Methodology}

\section{Random Digit Dial Survey}

The present study was conducted as part of a broader investigation of gambling and problem gambling in the Canadian province of Ontario. A random digit dial telephone survey of 6654 Ontario adults was conducted using a computer-assisted telephone interview (CATI). The household interviewee was randomly determined by requesting the interview be conducted with the adult $(18+)$ having the next birthday. There were exhaustive attempts to contact the person, which, in some cases meant phoning 36 times over several months to establish contact. The majority of the phoning occurred in the evening and on weekends. Most refusals were contacted again at a later time and asked to reconsider doing the survey. The survey was kept very short to increase the chances the person would participate. Phone calls were spread over a 9-month period, from March to November 2003, in order to mitigate against seasonal fluctuations in gambling behaviour and to maximize the chances of contacting the person. Using this strategy, we obtained a response rate of 51\% using the criteria of the Council of American Survey Research Organizations (CASRO, 1982).

\section{Retrospective Gambling Expenditure Question}

Of the sample of $6654,59.9 \%$ did not progress beyond a 5-minute screening interview, since they reported spending less than $\$ 9$ on gambling in a typical month. The remaining respondents were administered a longer survey instrument which asked about their gambling behavior in detail. Each of these individuals was randomly asked one of 12 different questions that enquired about past month gambling expenditure. A total of 2424 individuals, representing $36 \%$ of the initial sample, provided quantifiable answers. There were three main elements of the question that were varied. The first concerned whether the person was asked about 'spending' or 'coming out ahead or behind'. The second concerned whether the person was asked about their expenditure on 'gambling'; their total expenditure on 'lottery, raffle and instant win tickets, Sports Select, slot machines and table games at Ontario casinos and racetracks, horse race betting, and bingo'; or expenditure on each individual form of gambling. The third concerned whether the person was asked to estimate their expenditure for 'a typical month' or 'the last time they played'. Figure 1 illustrates the various segments of the question that were manipulated.

The 12 different questions were as follows:

A. Roughly how much money do you spend on gambling in a typical month?

B. Roughly how much money do you spend in total on lottery, raffle and instant win tickets; Sports Select; slot machines and table games at Ontario casinos and racetracks; horse race betting; and bingo in a typical month?

C. Roughly how much money do you spend on [specific gambling activity] in a typical month? ["lottery and instant win tickets"; "Sports Select"; "raffle or fundraising tickets"; "slot machines at Ontario casinos and racetracks"; "table games such as blackjack, roulette, craps, and poker at Ontario casinos"; "horse race betting"; "bingo"; and "gambling on anything else, such as out-of-province casinos; betting on sports with a bookie; internet gambling; or betting against other people on games such as pool, darts, video games, board games, cards, etc.']

D. Roughly how much money did you spend on [specific gambling activity] the last time you purchased/played [specific gambling activity]? Roughly how often do you 
purchase/play [specific gambling activity]. Would you say daily, 4-6 times a week, 1-3 times a month, 4-12 times a year, 1-3 times a year, or less than once a year?

E. Roughly how much money do you come out ahead or behind on gambling in a typical month?

F. Roughly how much money do you come out ahead or behind in total on lottery, raffle and instant win tickets; Sports Select; slot machines and table games at Ontario casinos and racetracks; horse race betting; and bingo in a typical month?

G. Roughly how much money do you come out ahead or behind on [specific gambling activity] in a typical month?

H. Roughly how much money did you come out ahead or behind on [specific gambling activity] the last time you purchased/played [specific gambling activity]? Roughly how often do you purchase/play [specific gambling activity]. Would you say daily, 4-6 times a week, 1-3 times a month, 4-12 times a year, 1-3 times a year, or less than once a year?

I. Roughly how much money do you spend on gambling in a typical month? What we mean here is how much you are ahead or behind, or your net win or loss in a typical month.

J. Roughly how much money do you spend in total on lottery, raffle and instant win tickets; Sports Select; slot machines and table games at Ontario casinos and racetracks; horse race betting; and bingo in a typical month? What we mean here is how much you are ahead or behind, or your net win or loss in a typical month.

K. Roughly how much money do you spend on [specific gambling activity] in a typical month? What we mean here is how much you are ahead or behind, or your net win or loss in a typical month.

L. Roughly how much money did you spend on [specific gambling activity] the last time you purchased/played [specific gambling activity]? What we mean here is how much you are ahead or behind, or your net win or loss on that occasion. Roughly how often do you purchase/play [specific gambling activity]. Would you say daily, 4-6 times a week, 1-3 times a month, 4-12 times a year, 1-3 times a year, or less than once a year?

\section{Reliability}

The reliability of the person's answer to their Retrospective Gambling Expenditure Question was assessed by an additional question, later in the survey, that asked the person whether he/she had spent an amount gambling, in the past year, that was at least two-thirds of what they had reported earlier (a computer algorithm determined their projected yearly expenditures). Individuals' gambling expenditure estimates were flagged as potentially unreliable if they answered "no" to this question. People who reported winning money were not asked this Reliability Question nor were people who were administered Questions D, H, L, as these questions required too complicated a computer algorithm.

\section{Validity}

We assessed the relative validity of the 12 retrospective questions in two ways. First, we compared estimated expenditures, for each question, to actual gambling revenues in Ontario. Total Ontario gambling revenue from Ontario residents in 2003 is estimated to be $\$ 4,037,603,000$ (Williams \& Wood, 2004b). As there were approximately 9,441,668 adults $(18+)$ in Ontario in 2003, the average reported monthly net win/loss should be $-\$ 35.64$ (Note: throughout this paper negative signs denote a reported net loss whereas positive signs denote a 
reported net win). In the present study, $59.9 \%$ of the people surveyed did not receive the full survey because they indicated they spent less than $\$ 9$ in a typical month on gambling in the past year. The average monthly expenditure of this $59.9 \%$ of the sample is $-\$ 1.71$. Thus, for the total sample average to be $-\$ 35.64$, the average monthly expenditure of the remaining $40.1 \%$ should be $\mathbf{- \$ 8 6 . 2 9}$. We take this figure as the 'true' average monthly expenditure among our respondents. Although there are some caveats and pitfalls to consider (which we will outline later), we conclude that a question is more valid the more closely it generates expenditure estimate totals to this true figure.

We established validity in a second way, by comparing retrospective estimates to prospective estimates obtained from a random subset of the respondents $(n=364)$, who recorded their actual gambling expenditures, for a 30-day period, in a daily prospective diary. People who agreed to complete the prospective diaries were sent four 1-week diaries and four pre-paid envelopes. They were instructed to record their gambling activities starting on the first Monday after receiving the package and to continue for four consecutive weeks. Each day of the diary asked whether there had been any gambling activity or not. If there was, the person was asked to identify the type of gambling, the time spent, and their net win/loss. The diaries provided clear and complete instructions on how to calculate net daily wins or losses for different types of gambling. ${ }^{1}$ At the end of each week the person was asked to mail in their completed diary. Participants were sent a cheque for $\$ 50$ upon receipt of all four diaries.

\section{Results}

\section{Estimated Gambling Expenditures}

As seen in table 1, median monthly gambling expenditure varied widely from a low of $-\$ 10$ to a high of $-\$ 50$ depending on how the question was asked. Asking people how much they 'came out ahead or behind' on gambling in the past month consistently produced the lowest median estimates (-\$11.06 average for Questions E, G, F, H). These amounts were much lower than obtained when asking people how much they 'spend' gambling ( $\$ 27.96$ average for Questions A, B, C, D). Asking people how much they 'spend' and then explaining that this means how much they 'come out ahead or behind', produced an intermediate amount (-\$20.91 average for Questions I, J, K, L).

Asking people how much they spend on 'gambling' produced slightly lower amounts (\$14.33 average for Questions E, I, A) compared to asking how much they spent 'in total on lottery, raffle and instant win tickets, Sports Select, slot machines and table games at Ontario casinos and racetracks, horse race betting, and bingo' ( $\$ 16.00$ average for Questions F, J, B). Somewhat higher amounts were obtained when people are asked how much they spend on each specific type of gambling in the past month and adding the totals ( $\$ 18.67$ average for Questions $\mathrm{G}, \mathrm{C}, \mathrm{K})$.

Finally, the highest amounts were obtained when asking people how much they spent on each specific activity 'the last time they purchased/played that activity' and then asking 'how often they purchase/play' that activity to derive a monthly estimate ( $\$ 30.90$ average for Questions H, L, D).

\section{Reliability}

Overall gambling expenditure reliability was poor. This is evidenced by the fact that only $37.3 \%$ of individuals 'passed' the Reliability Question, that is, endorsed that their yearly spending was at least two-thirds of what they had reported it to be five minutes earlier. The basis 
for this unreliability is uncertain. It could indicate that the original monthly figure provided was arbitrarily determined and inherently unreliable. Alternatively it could be that people have difficulty projecting their expenditures over a 12 month period, or that they are not psychologically prepared to accept or admit what their monthly spending projects to in terms of yearly spending.

There was significant variation in the percentage of people who endorsed the Reliability Question as a function of which Retrospective Gambling Expenditure question they had been asked. The following is the rank order of endorsement from highest to lowest: A (53.8\%), B (46.9\%), E (40.9\%), J (39.7\%), I (38.9\%), F (33.9\%), C (30.6\%), G (24.5\%), K (20.1\%). Unfortunately, what these results mostly illustrate is that Retrospective Gambling Expenditure questions most similar in wording to the Reliability Question received the highest endorsement. Questions C, G, K are the most dissimilar as they all asked about spending on each type of gambling. Questions A and B are the most similar in wording to the Reliability Question with the only difference being the time period asked.

\section{Validity based on Comparisons with Ontario Gambling Revenue}

Before considering which question produces average expenditure estimates that come closest to the true figure, it is important to determine the best way of calculating the averages. One important problem is that regular gamblers occasionally have very large wins and losses. These statistical outliers have a major influence on the averages, making it very difficult with small sample sizes (approximately 200 people per question in the present study) to establish what the 'true' average expenditures are, so as to compare them with actual revenues. Realistically, there would have to be thousands of people administered each retrospective question version to offset the impact of these outliers. To deal with this problem, we also computed mean expenditures under the following conditions: a) winsorizing the top and bottom $1 \%$ of the data for each question (this involves replacing the values with the next highest or lowest value plus one); and b) trimming (deleting) the top and bottom $1 \%$ of the data for each question. However, this is not a perfect solution as it tends to create averages that are somewhat too low, due to some very large and potentially legitimate values being winsorized or eliminated (in the present study there were eight people who reported monthly losses of between $-\$ 10,000$ to $-\$ 270,000$ ).

Another approach to calculating 'valid' averages is to eliminate unreliable or implausible estimates. Thus, we also computed mean expenditures when c) eliminating people who are not consistent in their estimate of expenditure (i.e., failed the Reliability Question); and d) eliminating people who report typically winning money or breaking even (a probabilistically unlikely outcome for people who gamble regularly). This latter approach, however, has the potential for creating averages that are somewhat too high due to the loss of a few legitimate winners and people who break even.

As expected, very few of the unadjusted raw averages came close to the true figure of -\$86.29 (see table 2). Only Question F had an unadjusted average (-\$87.35) that was close to the true average. However, this may be coincidental, as there was one individual reporting a $\$ 10,000$ loss in a typical month. When this person is eliminated the average falls to $-\$ 34.24$. There is reason to suspect this $\$ 10,000$ monthly estimate is not valid, as this person failed to endorse that his yearly spending was at least $\$ 80,000$ in the Reliability Question. The winsorized and trimmed averages decrease the impact of these sorts of outliers, and improve the figures somewhat. Question C had a winsorized average (-\$58.40) that was within $40 \%$ of the true figure. Question C also had a trimmed average (-\$53.07) that was within $40 \%$. Eliminating 
people who failed the Reliability Question was not that useful a strategy due to the positive correlation between the size of a person's monthly expenditure estimate and the likelihood of the person not endorsing the Reliability Question. As a consequence, eliminating unreliable estimates had the effect of producing averages that were consistently lower than the 'true' figure. Nonetheless, Question C had an average (-\$55.94) close to the true figure. Calculating averages after eliminating people reporting breaking even or winning proved more fruitful. With this strategy Questions B, C, E, G, J, and K had averages close to the true figure. However, it is important to bear in mind that this required eliminating a substantial part of the sample for some questions (e.g., 36\% for Question E). Questions B, C, and K had the fewest number of people eliminated with this procedure, and thus, may be inherently more valid (remember that all people in the study had already admitted to spending at least $-\$ 9$ in a typical month in order to be administered the full survey).

\section{Validity Based on Comparisons with Prospective Estimates}

Comparison with figures from the prospective diary is the second method for establishing the relative validity of the retrospective estimates (assuming the prospective diary gives more accurate accounting). A total of 364 people who gave a retrospective estimate on the telephone subsequently completed a four week prospective diary of their expenditures. Respondents began the diary phase of the study within a week of completing the phone survey and submitted their diaries on a weekly basis. At the end of the study respondents were asked if their net win/loss during that month was 'typical'. A total of $70.2 \%$ reported that it was, whereas $15.8 \%$ reported it was higher than usual and $14.0 \%$ reported it was lower than usual.

Table 3 reports respondents' retrospective estimates, their expenditure estimates from their 4-week prospective diaries, and the Pearson correlations between the retrospective estimates and the diary amounts. There was no trimming, winsorizing, or elimination of 'winners' when calculating expenditure estimates from the prospective diaries. Diary estimates are correlated with both the unaltered and winsorized retrospective estimates. In general, there was poor consistency between retrospective estimates and actual figures obtained from prospective diaries. The greatest consistency occurred with the retrospective estimates obtained for people administered Question C.

\section{Conclusion}

In general, retrospective estimates of gambling expenditures appear unreliable. First, only $37 \%$ of people endorsed that their yearly spending was at least two-thirds of what they had reported it to be five minutes earlier in the survey. Secondly, there is very little correlation between retrospective estimates of expenditures and subsequent amounts obtained by prospective diaries. Thirdly, very few retrospective estimates come close to matching actual revenues. It seems clear that most people either do not keep track of gambling expenditure, have a difficult time in quickly tabulating it, or else consider this such sensitive information that they distort the true figures.

Consistent with other research, it is also fairly evident that retrospective estimates of gambling expenditures are also strongly shaped by how the question is asked (Schwarz, 1999). In the present study, the median expenditures produced by some questions were five times higher than the median expenditures produced by of other questions. Questions that ask people how much they 'come out ahead or behind' on gambling produce much lower amounts than asking 
people how much they 'spend' on gambling. Asking people how much they 'spend' and then explaining that this means how much they 'come out ahead or behind', produces an intermediate amount. Asking people how much they spend on 'gambling' produces slightly lower amounts compared to asking how much they spend 'in total on lottery, raffle and instant win tickets, Sports Select, slot machines and table games at Ontario casinos and racetracks, horse race betting, and bingo'. The highest amounts are obtained when people are asked how much they spend on each specific type of gambling and adding the totals. Asking people how much they spent 'the last time they purchased/played that activity' and then asking 'how often they purchase/play' that activity produces much higher amounts than questions that ask for an aggregate estimate about monthly spending.

Of most importance, certain retrospective question wordings appear to be able to elicit estimates with better validity than others based on correspondence with actual gambling revenues and amounts obtained from prospective diaries. The question wording with the most robust evidence of validity is Question C: "Roughly how much money do you spend on [specific gambling activity] in a typical month?" (with totals from each activity then added together). Interestingly, this is a question wording that has been often used in gambling behaviour surveys and which has sometimes produced expenditures too high relative to actual revenues (see Williams \& Wood, 2004b). With this in mind, it may be also worth considering Question K, which perhaps has the second best evidence of validity as well as more intrinsic 'face validity": "Roughly how much money do you spend on [specific gambling activity] in a typical month? What we mean here is how much you are ahead or behind, or your net win or loss in a typical month". It is possible that the caveat, "what we mean here is how much you are ahead or behind", minimized misunderstandings on the part of the respondents, attuning them to the importance of calculating "net" expenditures, as opposed to total outlay (initial outlay plus winnings). We also observed that this caveat had a significant dampening effect on gambling expenditures in the present study relative to Question C. It is possible that this dampening effect may not be as strong if the caveat was mentioned only once (i.e., after asking about the first specific form of gambling), rather than routinely mentioning when asking about each specific form. However, it should be noted that while these results indicate that certain question wordings may elicit more valid expenditure estimates, replication of these findings and further research is warranted before developing a conclusive set of expenditure questions to be used survey-wide.

Efforts to enhance the validity of self reported gambling expenditures have value in and of itself. However, we wish to conclude this article by reiterating that the validity of these selfreports has important implications in two specific areas. The first is in the treatment of problem gamblers, where clinicians are very much reliant on gamblers' self-report of decreased gambling behavior, as there are no independent biochemical markers to validate these reports as there are in substance abuse. The second is in the area of government policy. As governments continue to accelerate the expansion of gambling opportunities for citizens, and as governments become ever more reliant on monies derived from gambling, it is crucial that we maintain an understanding of what proportion of government gaming revenue gets generated by certain categories of people. More specifically, in order to ensure that government sponsored gambling policies are both ethically and socially responsible, it is crucial that we gain a clear understanding of the proportion of government gaming revenues that are generated by people who occupy a lower socio-economic status, and especially by people who are problem gamblers. The use of valid expenditure questions, in gambling revenue studies, is an important step in realizing this goal. 


\section{References}

Abbott, M.W. \& Volberg, R.A. (2000). Taking the Pulse on Gambling and Problem Gambling in New Zealand: A Report on Phase One of the 1999 National Prevalence Survey. June 2000. New Zealand: Department of Internal Affairs, Government of New Zealand.

Access Economics (2002). Gambling Participation and Expenditure in the 1998-99 Household Expenditure Survey. Report produced for Tattersall's, December 2002. Available online at: www.accesseconomics.com.au/reports/tattsrebuttal.pdf

Australian Bureau of Statistics (2005). Household Expenditure Survey, Australia 2003-2004. ACT: Author.

Blaszczynski, A., Dumlao, V., Lange, M. (1997). How much do you spend gambling? Ambiguities in survey questionnaire items. Journal of Gambling Studies, 13, 237-252.

Council of American Survey Research Organizations (CASRO) (1982). On the Definition of Response Rates. Port Jefferson, New York: CASRO.

Bondolfi, G., Osiek, C., Ferrero, F. (2000). Prevalence estimates of pathological gambling in Switzerland. Acta Psychiatrica Scandinavica, 101(6), 473-475.

Carney, M.A., Tennen, H., Affleck, G., del Boca, F.K., Kranzler, H.R. (1998). Levels and patterns of alcohol consumption using timeline follow-back, daily diaries and real-time electronic interviews. Journal of Studies on Alcohol, 59, 447-454.

Corti, B., Binns, C.W., Howat, P.A., Blaze-Temple, D., et al. (1990). Comparison of 7-day retrospective and prospective alcohol consumption diaries in a female population in Perth, Western Australia: Methodological issues. British Journal of Addiction, 85, 379388.

Fowler, F.J. (1993). Survey Research Methods, Second Edition. London: Sage.

Gerstein, D., Murphy, S., Toce, M., Hoffmann, J., Palmer, A., Johnson, R., Larison, C., Chuchro, L., Bard, A., Engelman, L., Hill, M. A., Buie, T., Volberg, R., Harwood, H., Tucker, A., Christiansen, E., Cummings, W., and Sinclair, S. (1999). Gambling Impact and Behavior Study: Report to the National Gambling Impact Study Commission. Chicago: National Opinion Research Center.

Götestam, K. G., \& Johansson, A. (2003). Characteristics of gambling and problematic gambling in the Norwegian context: A DSM-IV-based telephone interview study. Addictive Behaviors, 28, 189-197.

Hodgins, D.C. \& Makarchuk, K. (2003). Trusting problem gamblers: Reliability and validity of self-reported gambling behavior. Psychology of Addictive Behaviors, 17, 244-248.

Johnson, J. and Bytheway, B. (2001). An evaluation of the use of diaries in a study of medication in later life. International Journal of Social Research Methodology, 4(3): 183-204.

Lemmens, P., Tan, E.S., Knibbe, R.A. (1992). Measuring quantity and frequency of drinking in a general population survey: A comparison of five indices. Journal of Studies on Alcohol, 53, 476-486.

McCusker, C.G. \& Gettings, B. (1997). Automaticity of cognitive biases in addictive behaviours: Further evidence with gamblers. British Journal of Clinical Psychology, 36, 543-554.

National Research Council (1999). Pathological Gambling: A Critical Review. Committee on the Social and Economic Impact of Pathological Gambling, Committee on Law and 
Justice, Commission on Behavioral and Social Sciences and Education, and the National Research Council. Washington, D.C.: National Academy Press.

Office for National Statistics (2004). Family Spending (2002-2003). A Report on the 2002-2003 Expenditure and Food Survey. London, England: Author.

O'Hare, T. (1991). Measuring alcohol consumption: A comparison of the retrospective diary and the quantity-frequency methods in a college drinking survey. Journal of Studies on Alcohol, 52, 500-502.

Productivity Commission (1999). Australia's Gambling Industries, Report No. 10, AusInfo, Canberra.

Schaeffer, N.C. (2000). Asking questions about threatening topics: A selective overview. In A.A. Stone \& J.S. Turkkan (eds.), The Science of Self-Report: Implications for Research and Practice (pp 105-121). Mahwah, NJ: Erlbaum.

Schwarz, N. (1999). Self-reports. How the questions shape the answers. American Psychologist, 2, 93-105.

Sproston, K., Erens, B., \& Orford, J. (2000). Gambling Behaviour in Britain: Results from the British Gambling Prevalence Survey. London: National Centre for Social Research.

Shakeshaft, A., Bowman, J.A., Sanson-Fisher, R.W. (1999). A comparison of two retrospective measures of weekly alcohol consumption: Diary and quantity/frequency index. Alcohol \& Alcoholism, 34, 636-645.

Sobell, L.C. \& Sobell, M.B. (1996). Alcohol timeline followback (TLFB) users' manual. Toronto: Addiction Research Foundation.

Statistics Canada (2003). Fact-sheet on gambling. Perspectives on Labour and Income March 2003. Ottawa, Canada: Author.

Statistics Canada (2005). Survey of Household Spending 2003. Ottawa, Ontario: Author.

Statistics New Zealand (1999). Gaming: an economically significant industry. Key Statistics September 1999. Available online at: http://www.stats.govt.nz/NR/rdonlyres/0C82D0F51C9E-43B7-AD1D-6A5DDD13FEFF/0/GamingIndustry.pdf.

Statistics New Zealand (2004). Household Economic Survey, Year Ended 30 June 2004. Auckland, NZ: Author.

Toneatto, T. (1999). Cognitive psychopathology of problem gambling. Substance Use \& Misuse, 34, 1593-1604.

Toneatto, T., Blitz-Miller, T., Calderwood, K., Dragonetti, R. \& Tsanos, A. (1997). Cognitive distortions in heavy gambling. Journal of Gambling Studies, 13, 253-267.

Tourangeau, R. (2000). Remembering what happened: Memory errors and survey reports. In A.A. Stone \& J.S. Turkkan (eds.), The Science of Self-Report: Implications for Research and Practice (pp 29-47). Mahwah, NJ: Erlbaum.

van der Heijden, P. G. M., Van Gils, G., Bouts, J., \& Hox, J. J. (2000). A comparison of randomized response, computer assisted interview, and face-to-face direct questioning: Eliciting sensitive information in the context of welfare and unemployment benefit. Sociological Methods and Research, 28, 505-537.

Volberg, R., Moore, W., Christiansen, E., Cummings, W., \& Banks, S. (1998). Unaffordable losses: Estimating the proportion of gambling revenues derived from problem gamblers. Gaming Law Review, 2(4), 349-360.

Werch, C.E. (1990). Two procedures to reduce response bias in reports of alcohol consumption. Journal of Studies on Alcohol, 51, 327-330. 
Williams, R.J. \& Wood, R.T. (2004a). The proportion of gaming revenue derived from problem gamblers: Examining the issues in a Canadian context. Analyses of Social Issues \& Public Policy, 4 (1), 33-45.

Williams, R.J. \& Wood, R.T. (2004b). The Demographic Sources of Ontario Gaming Revenue. Final Report submitted to the Ontario Problem Gambling Research Centre, June 23, 2004. 


\section{Author Note}

Robert T. Wood is an Associate Professor in the Department of Sociology at the University of Lethbridge, Lethbridge, Alberta, Canada (Robert.wood@ uleth.ca). Robert J.

Williams is a Professor in the School of Health Sciences and also the Coordinator for the Alberta Gaming Research Institute at the University of Lethbridge, Lethbridge, Alberta, Canada (Robert.williams@uleth.ca). Contact person for this paper is Dr. Williams.

This research was supported by funding from the Ontario Problem Gambling Research Centre. 


\section{Footnotes}

${ }^{1}$ The inside cover of the diary included the following instructions, regarding the calculation of net losses and wins:

Under "NET LOSS/WIN" indicate the difference between the amount of money you spent gambling and the amount you receive back as winnings.

○ In cases where the outcome is not determined on the same day (e.g., lottery tickets, sports betting, stock market), your net loss/win for the day is the amount you spent on the tickets or stocks (e.g., “-\$50”). If you subsequently win money from these tickets, etc., record the winnings on the day the winnings occurred (e.g., "+\$10"). In the case of stocks, options or futures that you purchased during the week but have not yet sold, simply record their value on the Sunday of that week.

○ In cases where you immediately reinvest your winnings (e.g., bought more lottery tickets or put the money back into the VLT), your net loss/win for the day is how much money you are ahead or behind from that activity at the end of the day.

- In calculating net loss/win be sure you do not include the money you spent going to the gambling venue or that you spent on food, drinks, etc. 


\begin{tabular}{|c|c|c|c|c|}
\hline \multirow{4}{*}{$\begin{array}{l}\text { Roughly } \\
\text { how much } \\
\text { money } \\
\text { do/did you }\end{array}$} & \multirow[t]{2}{*}{ spend } & on gambling & \multirow[t]{2}{*}{ in a typical month? } & $\begin{array}{l}\text { What we mean } \\
\text { here is how } \\
\text { much you are }\end{array}$ \\
\hline & & \multirow{2}{*}{$\begin{array}{l}\text { in total on lottery, raffle and } \\
\text { instant win tickets, Sports } \\
\text { Select, slot machines and table } \\
\text { games at Ontario casinos and } \\
\text { racetracks, horse race betting, } \\
\text { and bingo }\end{array}$} & & net win or loss. \\
\hline & \multirow{2}{*}{$\begin{array}{l}\text { come out } \\
\text { ahead or } \\
\text { behind }\end{array}$} & & \multirow{2}{*}{$\begin{array}{l}\text { last time you } \\
\text { purchased/played } \\
\text { (this activity)?; } \\
\text { How often do you } \\
\text { purchase/play (this } \\
\text { activity)? }\end{array}$} & \\
\hline & & $\begin{array}{l}\text { on specific gambling activity } \\
\text { (8 different types) }\end{array}$ & & \\
\hline
\end{tabular}

Figure 1. Segments of the Retrospective Gambling Expenditure question that were varied. 
Table 1. Rank Order of Question Wordings Producing the Lowest Median Monthly Expenditure Estimate to the Highest.

\begin{tabular}{|c|c|c|}
\hline $\mathrm{E}$ & $\begin{array}{l}\text { Roughly how much money do you come out ahead or behind on gambling in a typical } \\
\text { month? }\end{array}$ & $-\$ 10.00$ \\
\hline $\mathrm{G}$ & $\begin{array}{l}\text { Roughly how much money do you come out ahead or behind on [specific gambling } \\
\text { activity] in a typical month? }\end{array}$ & $-\$ 10.00$ \\
\hline $\mathrm{F}$ & $\begin{array}{l}\text { Roughly how much money do you come out ahead or behind in total on lottery, raffle } \\
\text { and instant win tickets; Sports Select; slot machines and table games at Ontario casinos } \\
\text { and racetracks; horse race betting; and bingo in a typical month? }\end{array}$ & $-\$ 10.00$ \\
\hline I & $\begin{array}{l}\text { Roughly how much money do you spend on gambling in a typical month? What we } \\
\text { mean here is how much you are ahead or behind, or your net win or loss in a typical } \\
\text { month. }\end{array}$ & $-\$ 13.00$ \\
\hline $\mathrm{H}$ & $\begin{array}{l}\text { Roughly how much money did you come out ahead or behind on [specific gambling } \\
\text { activity] the last time you purchased/played [specific gambling activity]? Roughly } \\
\text { how often do you purchase/play [specific gambling activity]. Would you say daily, 4-6 } \\
\text { times a week, } 1-3 \text { times a month, } 4-12 \text { times a year, } 1-3 \text { times a year, or less than once a } \\
\text { year? }\end{array}$ & $-\$ 14.25$ \\
\hline $\mathrm{J}$ & $\begin{array}{l}\text { Roughly how much money do you spend in total on lottery, raffle and instant win } \\
\text { tickets; Sports Select; slot machines and table games at Ontario casinos and racetracks; } \\
\text { horse race betting; and bingo in a typical month? What we mean here is how much you } \\
\text { are ahead or behind, or your net win or loss in a typical month. }\end{array}$ & $-\$ 18.00$ \\
\hline $\mathrm{A}$ & Roughly how much money do you spend on gambling in a typical month? & $-\$ 20.00$ \\
\hline B & $\begin{array}{l}\text { Roughly how much money do you spend in total on lottery, raffle and instant win } \\
\text { tickets; Sports Select; slot machines and table games at Ontario casinos and racetracks; } \\
\text { horse race betting; and bingo in a typical month? }\end{array}$ & $-\$ 20.00$ \\
\hline $\mathrm{C}$ & $\begin{array}{l}\text { Roughly how much money do you spend on [specific gambling activity] in a typical } \\
\text { month? }\end{array}$ & $-\$ 22.00$ \\
\hline $\mathrm{K}$ & $\begin{array}{l}\text { Roughly how much money do you spend on [specific gambling activity] in a typical } \\
\text { month? What we mean here is how much you are ahead or behind, or your net win or } \\
\text { loss in a typical month. }\end{array}$ & $-\$ 24.00$ \\
\hline $\mathrm{L}$ & $\begin{array}{l}\text { Roughly how much money did you spend on [specific gambling activity] the last time } \\
\text { you purchased/played [specific gambling activity]? What we mean here is how much } \\
\text { you are ahead or behind, or your net win or loss on that occasion. Roughly how often } \\
\text { do you purchase/play [specific gambling activity]. Would you say daily, } 4-6 \text { times a } \\
\text { week, 1-3 times a month, 4-12 times a year, 1-3 times a year, or less than once a year? }\end{array}$ & $-\$ 28.60$ \\
\hline $\mathrm{D}$ & $\begin{array}{l}\text { Roughly how much money did you spend on [specific gambling activity] the last time } \\
\text { you purchased/played [specific gambling activity]? Roughly how often do you } \\
\text { purchase/play [specific gambling activity]. Would you say daily, 4-6 times a week, 1-3 } \\
\text { times a month, 4-12 times a year, 1-3 times a year, or less than once a year? }\end{array}$ & $-\$ 49.85$ \\
\hline
\end{tabular}


Table 2. Self-Reported Past Month Gambling Expenditure for Each Retrospective Expenditure Question.

\begin{tabular}{|c|c|c|c|c|c|c|c|c|c|c|}
\hline Question & $\mathrm{N}$ & Average & $\begin{array}{c}\text { Average } \\
\text { (top \& } \\
\text { bottom } 1 \% \\
\text { winsorized) }\end{array}$ & $\begin{array}{l}\text { Average } \\
\text { (top \& } \\
\text { bottom 1\% } \\
\text { trimmed) }\end{array}$ & $\begin{array}{l}\text { Average } \\
\text { (unreliable } \\
\text { \& winners } \\
\text { removed) }\end{array}$ & $\begin{array}{l}\text { Average } \\
\text { (only } \\
\text { people } \\
\text { reporting } \\
\text { losses) } \\
\end{array}$ & Median & Mode & $\begin{array}{c}\% \\
\text { breaking } \\
\text { even }\end{array}$ & $\begin{array}{c}\% \\
\text { winners }\end{array}$ \\
\hline A & 223 & $-\$ 38.21$ & $-\$ 36.73$ & $-\$ 33.73$ & $-\$ 41.22$ & $-\$ 49.53$ & $-\$ 20.00$ & $-\$ 20.00$ & $13.5 \%$ & $3.6 \%$ \\
\hline B & 207 & $-\$ 17.14$ & $-\$ 30.66$ & $-\$ 32.25$ & $-\$ 43.90$ & $-\$ 54.38$ & $-\$ 20.00$ & $-\$ 10.00$ & $11.2 \%$ & $4.3 \%$ \\
\hline $\mathrm{C}$ & 193 & $-\$ 32.22$ & $-\$ 58.40$ & $-\$ 53.07$ & $-\$ 55.94$ & $-\$ 73.26$ & $-\$ 22.00$ & $-\$ 10.00$ & $5.7 \%$ & $5.7 \%$ \\
\hline $\mathrm{D}$ & 188 & $-\$ 763.58$ & $-\$ 376.92$ & $-\$ 283.20$ & N/A ${ }^{1}$ & $-\$ 858.42$ & $-\$ 49.85$ & $-\$ 20.00$ & $0 \%$ & $7.4 \%$ \\
\hline $\mathrm{E}$ & 197 & $-\$ 28.71$ & $-\$ 25.66$ & $-\$ 23.08$ & $-\$ 37.37$ & $-\$ 57.67$ & $-\$ 10.00$ & 0 & $27.4 \%$ & $8.1 \%$ \\
\hline $\mathrm{F}$ & 188 & $-\$ 87.35$ & $-\$ 20.32$ & $-\$ 18.60$ & $-\$ 14.05$ & $-\$ 157.89$ & $-\$ 10.00$ & 0 & $26.6 \%$ & $8.5 \%$ \\
\hline G & 219 & $-\$ 24.20$ & $-\$ 30.22$ & $-\$ 24.73$ & $-\$ 28.86$ & $-\$ 89.51$ & $-\$ 10.00$ & 0 & $15.5 \%$ & $18.7 \%$ \\
\hline $\mathrm{H}$ & 217 & $-\$ 1047.67$ & $+\$ 88.68$ & $+\$ 52.79$ & N/A ${ }^{1}$ & $-\$ 2234.35$ & $-\$ 14.25$ & 0 & $15.6 \%$ & $17.6 \%$ \\
\hline I & 202 & $+\$ 2.10$ & $-\$ 20.92$ & $-\$ 21.30$ & $-\$ 29.99$ & $-\$ 36.85$ & $-\$ 13.00$ & $-\$ 10.00$ & $12.4 \%$ & $9.9 \%$ \\
\hline $\mathbf{J}$ & 203 & $-\$ 25.04$ & $-\$ 15.19$ & $-\$ 18.50$ & $-\$ 25.32$ & $-\$ 67.22$ & $-\$ 18.00$ & $-\$ 20.00$ & $14.3 \%$ & $8.9 \%$ \\
\hline $\mathrm{K}$. & 194 & $+\$ 430.48$ & $-\$ 42.02$ & $-\$ 43.60$ & $-\$ 42.44$ & $-\$ 65.36$ & $-\$ 24.00$ & $-\$ 10.00$ & $8.7 \%$ & $8.8 \%$ \\
\hline $\mathrm{L}$ & 193 & $-\$ 1519.35$ & $-\$ 462.60$ & $-\$ 217.92$ & N/A ${ }^{1}$ & $-\$ 1930.48$ & $-\$ 28.60$ & $-\$ 40.00$ & $0 \%$ & $15.5 \%$ \\
\hline $\begin{array}{c}\text { All } \\
\text { Questions } \\
\text { Combined }\end{array}$ & 2424 & $-\$ 255.03$ & $-\$ 45.93$ & $-\$ 42.62$ & N/A & $-\$ 471.45$ & $-\$ 20.00$ & 0 & $11.8 \%$ & $10.7 \%$ \\
\hline
\end{tabular}

1. The reliability question was not asked for people who received question $\mathrm{D}, \mathrm{H}$, and $\mathrm{L}$ as it was too complicated an algorithm. Note: Bolded boxes indicate sums that are within $40 \%$ of the 'true value'. 
Table 3. Retrospective Estimates of Expenditure Compared to the Prospective Diary Amounts as a Function of Retrospective Question.

\begin{tabular}{|c|c|c|c|c|c|}
\hline Question & $\mathrm{n}$ & $\begin{array}{c}\text { Retrospective } \\
\text { Average }\end{array}$ & $\begin{array}{c}\text { Prospective } \\
\text { Average }\end{array}$ & $\begin{array}{c}\text { Pearson } \\
\text { Correlation }\end{array}$ & $\begin{array}{c}\text { Correlation } \\
\text { (winsorized } \\
\text { retrospective } \\
\text { data) }\end{array}$ \\
\hline $\mathrm{C}$ & 27 & $-\$ 65.76$ & $-\$ 118.64$ & .72 & .52 \\
\hline $\mathrm{K}$ & 37 & $-\$ 75.11$ & $-\$ 121.04$ & .40 & .45 \\
\hline $\mathrm{J}$ & 30 & $-\$ 35.57$ & $-\$ 128.88$ & .39 & .34 \\
\hline $\mathrm{L}$ & 33 & $-\$ 9272.01$ & $-\$ 91.80$ & .27 & .61 \\
\hline $\mathrm{F}$ & 28 & $-\$ 374.07$ & $-\$ 31.76$ & .24 & .41 \\
\hline $\mathrm{E}$ & 22 & $-\$ 33.14$ & $-\$ 33.24$ & .23 & -.03 \\
\hline $\mathrm{D}$ & 31 & $-\$ 418.22$ & $-\$ 347.92$ & .02 & .12 \\
\hline H & 36 & $+\$ 463.93$ & $+\$ 656.00$ & 0 & .30 \\
\hline $\mathrm{B}$ & 25 & $-\$ 23.40$ & $-\$ 71.48$ & -.11 & -.18 \\
\hline G & 30 & $-\$ 8.77$ & $-\$ 133.12$ & -.17 & .03 \\
\hline $\mathrm{I}$ & 36 & $-\$ 34.67$ & $+\$ 67.68$ & -.17 & -.24 \\
\hline A & 29 & $-\$ 76.00$ & $+\$ 31.32$ & -.51 & -.04 \\
\hline
\end{tabular}

